\title{
Association of healthy lifestyle with risk of obstructive sleep apnea: a cross-sectional study
}

Xueru Duan ${ }^{1,2 \dagger}$, Jun Huang ${ }^{3 \dagger}$, Murui Zheng ${ }^{4 \dagger}$, Wenjing Zhao ${ }^{5 \dagger}$, Lixian Lao ${ }^{6}$, Haiyi Li ${ }^{7}$, Zhiwei Wang ${ }^{4}$, Jiahai Lu', Weiqing Chen ${ }^{1 *}$, Hai Deng ${ }^{6^{*}}$ and Xudong Liu ${ }^{2^{*}}$

\begin{abstract}
Background: No studies investigated the whole effect of modifiable lifestyle factors on OSA risk. This study aimed to examine the individual and combined effects of lifestyle factors on OSA risk among Chinese adults.

Methods: This cross-sectional study included 9733 participants aged 35 to 74 years from the baseline survey of Guangzhou Heart Study. OSA was evaluated by Berlin Questionnaire. The healthy lifestyle score (HLS), representing the overall effect of lifestyles, was derived from seven lifestyle factors: active smoking, passive smoking, alcohol, diet, waist-hip ratio, leisure-time physical activity, and mental status. Odds ratio (OR) with 95\% confidence interval (Cl) was calculated using the multivariate logistic regression model.
\end{abstract}

Results: 8107 participants were divided into the non-OSA group and 1626 participants into the OSA group. No passive smoking (OR 0.83, 95\% Cl 0.74-0.94), healthy waist-hip ratio (OR $0.67,95 \% \mathrm{Cl} 0.58-0.77)$ and healthy mental status (OR $0.45,95 \% \mathrm{Cl} 0.29-0.73$ ) were associated with a reduced risk of OSA after adjusting for confounders, while others not. Participants with higher HLS were negatively associated with OSA risk $\left(P_{\text {-trend }}<0.001\right)$. In comparison to the participants with 0-3 HLS, the OR for participants with 4, 5, 6, and $7 \mathrm{HLS}$ was 0.68 ( $95 \% \mathrm{Cl} 0.56-0.84), 0.71(95 \% \mathrm{Cl}$ $0.59-0.86$ ), 0.62 ( $95 \% \mathrm{Cl} 0.51-0.76$ ) and 0.49 (95\% Cl 0.37-0.65) after adjusting for confounders. Every 1-score increment of HLS was associated with a $13 \%$ lower risk of OSA.

Conclusions: The results suggest that HLS reflecting the combined effect of multiple-dimensional lifestyle factors was inversely associated with OSA risk. Preventive strategies integrating multiple lifestyle factors may provide a more feasible approach for OSA prevention.

\footnotetext{
*Correspondence: chenwq@mail.sysu.edu.cn; doctordh@hotmail.com; xdliu. cn@hotmail.com

${ }^{\dagger}$ Xueru Duan, Jun Huang, Murui Zheng and Wenjing Zhao contributed equally to this work

1 Department of Epidemiology, School of Public Health, Sun Yat-Sen University, 7/F, Public Health Building, No.74, Zhongshan Second Road, Guangzhou 510080, China

2 School of Public Health, Guangdong Pharmaceutical University, No. 283 Jianghai Avenue, Haizhu District, Guangzhou 510310, China

${ }^{6}$ Department of Cardiology, Guangdong Cardiovascular Institute, Guangdong Provincial People's Hospital/Guangdong Academy of Medical Science, 5/F, Ying Tung Building, No.106, Zhongshan Second Road, Guangzhou 510080, China

Full list of author information is available at the end of the article
} original author(s) and the source, provide a link to the Creative Commons licence, and indicate if changes were made. The images or other third party material in this article are included in the article's Creative Commons licence, unless indicated otherwise in a credit line to the material. If material is not included in the article's Creative Commons licence and your intended use is not permitted by statutory regulation or exceeds the permitted use, you will need to obtain permission directly from the copyright holder. To view a copy of this licence, visit http://creativecommons.org/licenses/by/4.0/. The Creative Commons Public Domain Dedication waiver (http://creativeco mmons.org/publicdomain/zero/1.0/) applies to the data made available in this article, unless otherwise stated in a credit line to the data. 
Keywords: Lifestyle, Healthy lifestyle score, Obstructive sleep apnea

\section{Background}

Obstructive sleep apnea (OSA) is an increasingly common sleep disorder characterized by repeated collapse of the upper airway during sleep, resulting in recurrent oxyhemoglobin desaturation and periodic reductions or cessations in ventilation, with consequent hypoxia, hypercapnia, sleep fragmentation, or arousals from sleep $[1,2]$. The prevalence of OSA was escalating worldwide recently and presented prodigious regional disparity with $9-38 \%$ in Europe and North America and $8.8-24.2 \%$ in China $[2,3]$. It was estimated that a 5 -year incidence of OSA was about $7-11 \%$ in middleaged adults [2]. Evidence from cohort studies indicated that undiagnosed OSA, with or without symptoms, was an important contributor to cardiovascular, metabolic, and neurocognitive effects, as well as increased likelihood of motor vehicle accidents and diminished quality of life [4]. Nearly one billion adults aged 30-69 years worldwide were estimated to have OSA with 425 million requiring treatment, generating a high economic and social burden [5].

Several risk factors have been demonstrated to be associated with the occurrence and development of OSA, especially overweight, male, older age, anomalies of craniofacial structure, and hereditary factors $[6,7]$. Recent studies have shown that lifestyle factors, including aerobic physical activity, diet, smoking, and alcohol drinking, were correlated with the occurrence and severity of OSA. Independent of known risk factors for OSA, increased levels of physical activity, including walking, were associated with a prevalence of OSA [8]. Simpson et al. found that low levels of occupational activity and leisure exercise were associated with moderate-severe OSA in a study with case-control design [9]. Several population-based studies have demonstrated alcoholics and smokers were more likely to have high-risk OSA [10-12]. A less healthy dietary profile with lower whole-grain intake and increased red/processed meat consumption was linked with moderateto-more severe OSA, which were partially explained by reductions in slow-wave sleep, consequently leading to increased fragmented sleep and adiposity [13]. Besides, psychological status was also found to play an important role in the occurrence and development of OSA $[14,15]$; individuals with psychiatric disorders, especially major depressive disorder, were associated with elevated levels of OSA [15].

Lifestyle behaviors often coexist and may play an interactive effect. Several epidemiological studies constructed lifestyle indices to capture the overall role of multi-dimensional lifestyle factors on health issues [16-18]. However, to date, most present studies on OSA focus on a single-dimension lifestyle factor (mainly exercise or diet), and no one considered the overall effect of multi-dimension lifestyles on OSA. Moreover, the benefits of lifestyle intervention in the management of OSA patients are highlighted, but the effect of primary prevention for OSA by healthy lifestyle is neglected.

Accordingly, based on the guideline for primary care of adult obstructive sleep apnea [19] and prior evidence $[20,21]$, we developed a healthy lifestyle index that contained seven potential modifiable lifestyle factors-active smoking, passive smoking, alcohol, diet, waist-hip ratio, leisure-time physical activity, and mental status, to examine the combined effect of these lifestyle factors on OSA among Chinese adults.

\section{Study design and methods \\ Setting and subjects}

The data of this study was derived from the baseline survey of Guangzhou Heart Study (GZHS), an ongoing population-based prospective cohort study. The GZHS baseline survey was conducted from 2015 to 2017, and 12,013 subjects aged 35 years or above and permanently residing in Guangzhou were recruited by the multistage sampling method [22, 23]. Detailed information about GZHS has been reported in our previous reports $[22,23]$. Among 12,013 participants, 2280 subjects were excluded due to the following conditions: more than 74 years old $(n=1043)$, lack of OSA-related data $(n=5)$, suffering from the chronic obstructive pulmonary disease $(n=678)$ or cardiovascular disease $(n=554)$. A detailed

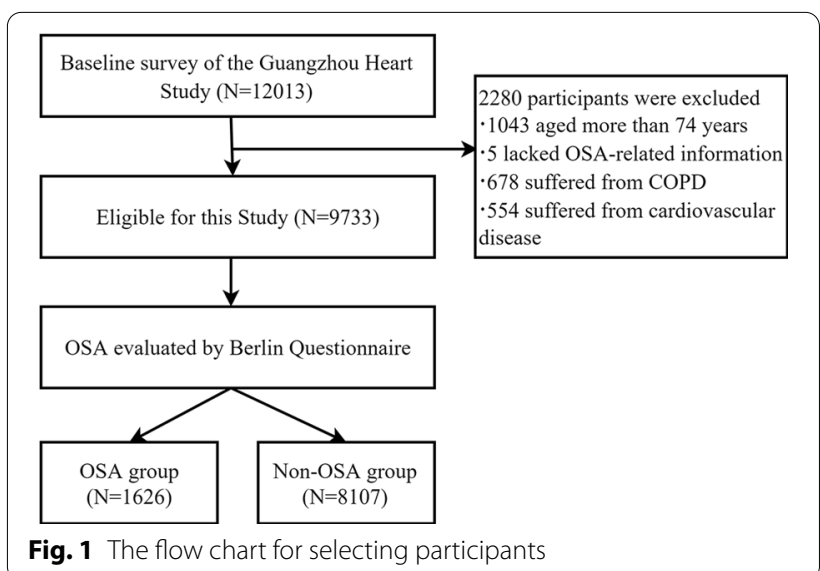


flow chart for selecting participants is shown in Fig. 1. Overall, 9733 participants were included for further analysis. This study was approved by the Ethical Committee of Guangdong Provincial People's Hospital and Ethical Review Committee for Biomedical Research, School of Public Health, Sun Yat-sen University. The study was performed in accordance with the Declaration of Helsinki and written informed consent was obtained from each participant before they joined in the study.

\section{OSA ascertainment}

OSA was determined by the Berlin Questionnaire (BQ), a tool developed for assessing OSA risk in the primary care settings with the sensitivity of $77 \%$ and the specificity of $44 \%$ among the general population [21]. BQ contained 10 questions in three categories: snoring and cessation of breathing (category 1), symptoms of excessive daytime sleepiness (category 2), body mass index (BMI), and hypertension (category 3 ). High risk in category 1 and category 2 was defined by persistent symptoms (>3-4 times/week) in at least two questions of each category and in category 3 was defined by the history of hypertension or BMI higher than $30 \mathrm{~kg} / \mathrm{m}^{2}$. Subjects who were considered high-risk for OSA should be at high risk at least two categories and were distributed to the OSA group, otherwise, subjects were considered low-risk for OSA and distributed to the non-OSA group [24].

\section{Assessment of lifestyle factors}

Questionnaires conducted with a face-to-face approach and physical examination were used to collect information of seven about lifestyle factors. A structured questionnaire was adopted to collect exposure information of smoking and alcohol drinking. Each subject was asked to report their current and prior smoking status. Participants were classified as nonsmokers if they had never smoked, as former smokers if they ever smoked but quitted smoking currently, as current smokers if they smoked frequently or occasionally when being recruited into the study. Besides, participants were required to answer whether they had exposed to smoke exhaled by other people in daily life or in workplace; if they answered "Yes", then the frequency of exposure for more than $15 \mathrm{~min}$ per day (almost every day, $\geq$ three days per week, one to three days per week, less than one day per week, and unknown) was further required to answer. Active smoking was defined as current smoking at the time of recruitment to the study and passive smoking was defined as exposure to the smoke exhaled from smokers more than $15 \mathrm{~min}$ at least one day per week [25]. Information on alcohol consumption was also assessed and participants were required to report their current status of alcohol drinking: "frequent drinking", "occasional drinking" and "never drinking or alcohol cessation". Occasional or frequent alcohol consumption was considered as alcohol drinking.

Dietary information was obtained by a 22 -item food frequency questionnaire (FFQ) and each participant was required to report the intake frequency of each food item (< once per month, 1-3 times per month, 1-3 times per week, 4-6 times per week and $\geq$ once per day) over the past year. A total of 12 major food items in FFQ were used to establish a diet quality score based on the Chinese Dietary Guidelines (2016) [26] and Guideline for primary care of adult obstructive sleep apnea (2018) [19]. Fruit and vegetables were separately assigned one point if they were consumed more than three times per week; whole grains, legumes, nuts, dairy, poultry, and fish were separately assigned one point if they were consumed at least once per week; red meat was assigned one point if it was consumed less than once per week; high-salt foods, fried foods, and sugary beverages were separately assigned one point if they were not consumed or consumed less than once per month. If the intake frequency of one food item did not meet the corresponding criteria aforementioned, a point of 0 was assigned to this item. Accordingly, the diet quality score ranged from 0 (lowest) to 12 (highest). A healthy diet was defined as the diet quality score higher than the median value, namely the score $\geq 7$.

Waist-hip ratio (WHR) was included as an indicator of abdominal obesity, because the distribution of abdominal fat accumulation had a stronger relationship with obesity-related diseases when compared with the body fat distribution [27]. Waist and hip circumference were measured three times in succession using standard instruments. The waist-hip ratio was calculated as the mean of waist circumference divided by the mean of hip circumference. The waist-hip ratio of $\geq 0.90$ for males and of $\geq 0.85$ for females was defined as abdominal obesity and considered unhealthy [28].

Leisure-time physical activity (LTPA) was assessed by a modified Global Physical Activity Questionnaire [29]. The total volume of LTPA was defined as the sum of the volume of eight general categories of most common activities including stroll, Tai Chi/Qigong, brisk walking/ health exercises/Yangko, long-distance running/aerobics dancing, swimming, ball games (basketball, table tennis, badminton, et al.), bicycling, and housework. The volume of each activity was calculated by multiplying the activity duration by frequency and then by the intensity (quantified by the value of metabolic equivalent, MET). Detailed evaluation of the volume of physical activity was shown in our previous report [22]. According to World Health Organization (WHO) guidelines on physical activity, adults should do at least 150-300 min of moderateintensity aerobic physical activity, or at least $75-150 \mathrm{~min}$ 
of vigorous-intensity aerobic physical activity, or an equivalent combination of moderate- and vigorousintensity activity throughout the week [30]; this means performing the activities with at least 10.0 MET-hours/ week to achieve the minimum level of the recommended standard.

Mental status including depression and anxiety was measured by the Center for Epidemiologic Studies Depression Scale (CES-D) and Zung's self-rating anxiety scale (SAS), respectively $[31,32]$. The range of CES-D scores was 0 to 60 , with a threshold of 16 or greater being considered as depression. The SAS index score ranged from 25 to 100 with a threshold of 45 or greater being considered as having anxiety. The participant who had either depression or anxiety was identified as having an unhealthy mental status.

\section{Derivation of the healthy lifestyle score}

The healthy lifestyle score (HLS) was created based on seven modifiable lifestyle factors: active smoking, passive smoking, alcohol, diet, waist-hip ratio, leisure-time physical activity, and mental status. Each lifestyle factor was dichotomized as healthy or unhealthy and each factor was then assigned a score of 0 and 1 for unhealthy and healthy, respectively. Healthy criteria for lifestyle factors were: no active smoking, no passive smoking, no current alcohol drinking, having a healthy diet (the diet quality score $\geq 7$ ), having a healthy weight (WHR $<0.90$ in males or $<0.85$ in females), being physically active (meeting the WHO guideline on physical activity), and having a healthy mental status (having neither depression nor anxiety). More details can be seen in Additional file 1: Table S1. HLS was the total sum of the score of seven lifestyle factors. Consequently, the healthy lifestyle score ranged from zero (least healthy) to seven (healthiest) points.

\section{Potential confounding factors}

The structured questionnaire aforesaid and physical examination were also used to collect information of demographic characteristics and history of diseases, including age (years), sex (male, female), education (primary school or lower, junior high school, senior high school, and college or above), marital status (married and others), retirement status (yes, no), hypertension (physician-diagnosed, or systolic blood pressure $\geq 140 \mathrm{mmHg}$, or diastolic blood pressure $\geq 90 \mathrm{mmHg}$ ), diabetes (physician-diagnosed, or fasting blood glucose $\geq 7.0 \mathrm{mmol} / \mathrm{L}$ ) [33] and dyslipidemia (physician-diagnosed, or serum cholesterol of $\geq 5.2 \mathrm{mmol} / \mathrm{L}$, or low density lipoprotein cholesterol of $\geq 3.4 \mathrm{mmol} / \mathrm{L}$, or triglyceride of $\geq 1.7 \mathrm{mmol} / \mathrm{L}$ ) [34]. Height and weight were measured for three consecutive times, and BMI was calculated as mean of weight divided by mean of height squared $\left(\mathrm{kg} / \mathrm{m}^{2}\right)$. The mean of three measurements of neck circumference was calculated $(\mathrm{cm})$.

\section{Statistical analysis}

Kolmogorov-Smirnov test was used to examine the normality. The continuous variables with normal distribution were represented by mean and standard deviation (SD), and the continuous variables with non-normal distribution were represented by median and quartile range (IQR). The distribution of categorical variables was expressed as frequency and percentage. The distribution difference of demographic characteristics, history of diseases, and other covariates between the non-OSA group and the OSA group was evaluated by t-test, or Wilcoxon rank-sum test, or chi-square test, correspondingly. Cochran-Armitage trend test was used to examine whether the distribution of HLS between the non-OSA group and the OSA group was significant. The associations between HLS and its components were manifested by the spearman correlation coefficient $\left(r_{s}\right)$. Logistic regression was used to estimate unadjusted and adjusted odds ratios (ORs) and 95\% confidence intervals (CIs) to demonstrate the individual and overall impact of lifestyle factors on OSA risk.

Stratified analyses were performed by sex, retirement status, and history of dyslipidemia. The multiplicative interaction of HLS with sex, retirement status, and history of dyslipidemia was examined respectively by using the likelihood ratio test, with a comparison of the likelihood scores of the two models with and without the interaction items.

Several sensitivity analyses were conducted to examine the robustness of our results. Each of the seven lifestyle factors was excluded in turn from HLS and repeated analyses were conducted to examine the stability of the HLS. The neck circumference was further adjusted in the multivariate model to consider the potential influence of fluid accumulation in the neck on OSA. Repeated analyses were also done by using STOP-Bang Questionnaire [35] to determine OSA, by using median in place of WHO-recommended cut-off value of LTPA in generating HLS on account of the fact that the volume of LTPA met the WHO recommendations for most participants (85.7\%), by excluding subjects aged 65 years or above to rule out the effects of age-related factors, and by excluding subjects with BMI of less than $18.5 \mathrm{~kg} / \mathrm{m}^{2}$ to rule out unknown bias brought by underweight.

All analyses were performed with $\mathrm{R}$ software (version 3.6.3). Two-sided $P$ values were computed and $\alpha$ less than 0.05 was considered significant. 


\section{Results}

A total of 9733 participants were included in this study, of which 8107 participants (83.29\%) were divided into the non-OSA group and 1626 participants (16.71\%) into the OSA group. The means of age (58.53 vs. 55.48 years), BMI (26.34 vs. $23.54 \mathrm{~kg} / \mathrm{m}^{2}$ ), waist-hip ratio (0.92 vs. 0.87 ) and neck circumference $(36.59$ vs. $34.17 \mathrm{~cm})$ in the OSA group were all larger than those in the non-OSA group. In comparison to the non-OSA participants, participants with OSA were more likely to be male and married, to have a lower level of education, to have diabetes and dyslipidemia, to be retirees, to smoke (whatever actively or passively) or drink alcohol, to have worse mental status, were less likely to have an active leisure-time physical activity, to have a higher dietary quality score or healthy lifestyle score (Table 1). In Additional file 1: Table S2, seven individual lifestyle factors were all strongly correlated with HLS (all $P<0.001$ ).

For individual lifestyle factors, no passive smoking (OR 0.83, 95\% CI 0.74-0.94), healthy waist-hip ratio (OR $0.67,95 \%$ CI $0.58-0.77$ ) and healthy mental status (OR 0.45 , 95\% CI 0. 29-0.73) were associated with a lower risk of OSA, while others not (Table 2). When considering the overall effect of all healthy lifestyle factors after adjusting for potential confounders, a lower risk of OSA was significantly associated with an increment of HLS $\left(P_{\text {-trend }}<0.001\right)$ (Table 3$)$. In comparison to the participants with 0-3 HLS, the OR for participants with 4, 5, 6, and 7 HLS was 0.68 (95\% CI 0.56-0.84), 0.71 (95\% CI $0.59-0.86), 0.62$ (95\% CI $0.51-0.76)$, and 0.49 (95\% CI $0.37-0.65)$, respectively, after adjusting for potential confounders. Every 1-point increment of HLS was associated with $13 \%$ (OR $0.87,95 \%$ CI $0.83-0.92$ ) reduced risk of OSA.

In sensitivity analysis, seven repeated analyses were conducted by excluding one factor from HLS in turn and consistent protective effect by HLS was observed (Additional file 1: Table S3). Besides, repeated analyses also yielded similar results by using STOP-Bang Questionnaire to determine OSA, by using median in place of WHO-recommended cut-off value of LTPA in generating HLS, by excluding subjects aged 65 years or more, and by excluding participants with BMI less than $18.5 \mathrm{~kg} / \mathrm{m}^{2}$, and by further adjustment for neck circumference (Additional file 1: Tables S4-S8).

In stratified analyses, a remarkably reduced risk of OSA was observed with the increase of HLS in both genders (Table 4), in both retirees and non-retirees (Table 5), and in subjects with and without dyslipidemia (Table 6). When comparing the highest with the lowest categories of HLS (7 vs. $\leq 3)$, the OR for male, female, retirees, nonretirees, subjects with dyslipidemia and subjects without dyslipidemia was 0.55 (95\% CI 0.37-0.82), 0.38 (95\% CI
0.24-0.62), 0.39 (95\% CI 0.24-0.60), 0.66 (95\% CI 0.450.97), 0.40 (95\% CI 0.23-0.69), 0.55 (95\% CI 0.40-0.75), respectively, after adjustment for confounders. However, by using the multiplicative interaction model, a significant interaction of HLS with retirement status $\left(P_{\text {-interaction }}<0.001\right)$ and history of dyslipidemia $\left(P_{\text {-interac- }}\right.$ tion $<0.001)$ but rather than with $\operatorname{sex}\left(P_{\text {-interaction }}=0.463\right)$ was observed.

\section{Discussion}

To the best of our knowledge, this is the first large-scale population-based study in China to investigate both individual and overall effect of lifestyle factors on OSA risk. We found that HLS constituted by seven modifiable lifestyle factors (active smoking, passive smoking, alcohol, diet, waist-hip ratio, leisure-time physical activity, and mental status) was adversely associated with OSA risk. The stratified and sensitivity analyses yielded consistent results. These provided important evidence for adopting a healthy lifestyle to prevent OSA among the general population.

Plenty of studies have examined the association between individual component of HLS and OSA risk $[14,36-40]$, whereas up-to-date no study examined the overall effect of multiple lifestyle factors on the risk of OSA. Our study created a new variable of HLS, which reflected the overall effect of the seven most common modifiable lifestyle factors including active smoking, passive smoking, alcohol, diet, waist-hip ratio, leisure-time physical activity, and mental status. Our study found that HLS was negatively associated with the risk of OSA and three stratified analyses and five sensitivity analyses yielded similar consistent results, indicating that our results were robust and stable. Our findings on OSA were consistent with those reports on other sleep-related problems such as sleep disturbances [41] and sleep disruption [42], though the lifestyle components and overall effect indexes were different across these studies. Liu and colleagues defined five health-risk behaviors including current smoking, current drinking, unhealthy eating habits, insufficient leisure activities, and physical inactivity among the Chinese elderly, and found that the risk of sleep disturbances was positively correlated with the number of multiple health-risk behaviors [41]. A crosssectional study among postmenopausal Iranian women found that the total score of ten lifestyle factors, including physical health, physical activity, weight control and nutrition, psychological health, spiritual health, social health, medications, and narcotics avoidance, illness prevention, accident prevention, and environmental health, was inversely related to sleep disruption [42].

The four most common used lifestyle factors as well as three new factors (passive smoking, waist-hip ratio, and 
Table1 Baseline characteristics of the participants

\begin{tabular}{|c|c|c|c|}
\hline Characteristic & Non-OSA group $(\mathrm{N}=8107)$ & OSA group $(\mathrm{N}=1626)$ & $P$ \\
\hline Age, years, mean (S.D.) & $55.48(9.98)$ & $58.53(8.93)$ & $<0.001^{*}$ \\
\hline Sex, N (\%) & & & $<0.001^{\dagger}$ \\
\hline Male & $2469(30.45)$ & $804(49.45)$ & \\
\hline Female & $5638(69.55)$ & $822(50.55)$ & \\
\hline Education, N (\%) & & & $0.003^{\ddagger}$ \\
\hline Primary school or lower & $2879(35.51)$ & $590(36.28)$ & \\
\hline Junior high school & $2081(25.67)$ & $397(24.42)$ & \\
\hline Senior high school & $2043(25.20)$ & $462(28.41)$ & \\
\hline College or above & $1104(13.62)$ & $177(10.89)$ & \\
\hline Marital status, N (\%) & & & $<0.001^{\dagger}$ \\
\hline Married & $7099(87.57)$ & $1476(90.77)$ & \\
\hline Others & $1008(12.43)$ & $150(9.23)$ & \\
\hline Active smoking, N (\%) & & & $<0.001^{\dagger}$ \\
\hline No & $6934(85.53)$ & $1292(79.46)$ & \\
\hline Yes & $1173(14.47)$ & $334(20.54)$ & \\
\hline Passive smoking, N (\%) & & & $0.004^{\dagger}$ \\
\hline No & $5071(62.55)$ & $955(58.73)$ & \\
\hline Yes & $3036(37.45)$ & $671(41.27)$ & \\
\hline Alcohol, N (\%) & & & $<0.001^{\dagger}$ \\
\hline Never or former drinking & $6404(78.99)$ & $1168(71.83)$ & \\
\hline Occasional or frequent drinking & $1703(21.01)$ & $458(28.17)$ & \\
\hline Dietary quality score, mean (S.D.) & $7.43(1.78)$ & $7.19(1.83)$ & $<0.001^{*}$ \\
\hline Waist-hip ratio, mean (S.D.) & $0.87(0.07)$ & $0.92(0.06)$ & $<0.001^{*}$ \\
\hline $\begin{array}{l}\text { Leisure-time physical activity, MET-h/week, } \\
\text { median (IQR) }\end{array}$ & $35.70(17.80,59.20)$ & $34.70(15.00,58.80)$ & $<0.001^{\S}$ \\
\hline Mental status, N (\%) & & & $0.100^{\dagger}$ \\
\hline Unhealthy & $96(1.18)$ & $28(1.72)$ & \\
\hline Healthy & $8011(98.82)$ & $1598(98.28)$ & \\
\hline Body mass index, $\mathrm{kg} / \mathrm{m}^{2}$, mean (S.D.) & $23.54(3.26)$ & $26.34(3.84)$ & $<0.001^{*}$ \\
\hline Neck circumference, cm, mean (S.D.) & $34.17(3.05)$ & $36.59(3.45)$ & $<0.001^{*}$ \\
\hline Hypertension, N (\%) & & & $<0.001^{\dagger}$ \\
\hline No & $5669(69.93)$ & $157(9.66)$ & \\
\hline Yes & $2438(30.07)$ & $1469(90.34)$ & \\
\hline Diabetes, N (\%) & & & $<0.001^{\dagger}$ \\
\hline No & $7509(92.62)$ & $1446(88.93)$ & \\
\hline Yes & $598(7.38)$ & $180(11.07)$ & \\
\hline Retirement status, N (\%) & & & $<0.001^{\dagger}$ \\
\hline No & $4149(51.18)$ & $683(42.00)$ & \\
\hline Yes & $3958(48.82)$ & $943(58.00)$ & \\
\hline Dyslipidemia, N (\%) & & & $<0.001^{\dagger}$ \\
\hline No & $2497(30.80)$ & $414(25.46)$ & \\
\hline Yes & $5610(69.20)$ & $1212(74.54)$ & \\
\hline Healthy lifestyle score, N (\%) & & & $<0.001^{\ddagger}$ \\
\hline $0-3$ & $684(8.43)$ & $272(16.73)$ & \\
\hline 4 & $1166(14.38)$ & $303(18.63)$ & \\
\hline 5 & $2310(28.49)$ & $514(31.61)$ & \\
\hline 6 & $2772(34.19)$ & $438(26.94)$ & \\
\hline 7 & $1175(14.49)$ & 99 (6.09) & \\
\hline
\end{tabular}

*P value for t-test

${ }^{\dagger} P$ for chi-square test

${ }^{\ddagger} P$ for Cochran-Armitage trend test

$\S P$ for Wilcoxon rank-sum test 
Table 2 Association between each lifestyle factor and OSA risk

\begin{tabular}{|c|c|c|c|c|c|}
\hline \multirow[t]{2}{*}{ Lifestyle factor score } & \multicolumn{2}{|l|}{$\mathbf{N}^{*}$} & \multicolumn{3}{|l|}{ Effect } \\
\hline & Non-OSA group & OSA group & Unadjusted OR (95\% CI) & Adjusted OR $(95 \% \mathrm{Cl})^{\dagger}$ & Adjusted OR $(95 \% \mathrm{Cl})^{\ddagger}$ \\
\hline \multicolumn{6}{|l|}{ Active smoking } \\
\hline Yes & 1173 & 334 & 1.00 & 1.00 & 1.00 \\
\hline No & 6934 & 1292 & $0.65(0.57,0.75)$ & $0.68(0.57,0.80)$ & $0.85(0.71,1.01)$ \\
\hline \multicolumn{6}{|l|}{ Passive smoking } \\
\hline Yes & 3036 & 671 & 1.00 & 1.00 & 1.00 \\
\hline No & 5071 & 955 & $0.85(0.76,0.95)$ & $0.85(0.76,0.96)$ & $0.83(0.74,0.94)$ \\
\hline \multicolumn{6}{|l|}{ Alcohol } \\
\hline Yes & 1703 & 458 & 1.00 & 1.00 & 1.00 \\
\hline No & 6404 & 1168 & $0.68(0.60,0.77)$ & $0.97(0.85,1.11)$ & $0.93(0.81,1.07)$ \\
\hline \multicolumn{6}{|l|}{ Diet } \\
\hline Unhealthy & 2447 & 570 & 1.00 & 1.00 & 1.00 \\
\hline Healthy & 5660 & 1056 & $0.80(0.72,0.90)$ & $0.92(0.82,1.04)$ & $0.95(0.84,1.08)$ \\
\hline \multicolumn{6}{|l|}{ Waist-hip ratio } \\
\hline Unhealthy & 4282 & 1246 & 1.00 & 1.00 & 1.00 \\
\hline Healthy & 3825 & 380 & $0.34(0.30,0.39)$ & $0.36(0.31,0.41)$ & $0.67(0.58,0.77)$ \\
\hline \multicolumn{6}{|c|}{ Leisure-time physical activity } \\
\hline Unhealthy & 1123 & 273 & 1.00 & 1.00 & 1.00 \\
\hline Healthy & 6984 & 1353 & $0.80(0.69,0.92)$ & $0.93(0.80,1.09)$ & $0.94(0.80,1.11)$ \\
\hline \multicolumn{6}{|l|}{ Mental status } \\
\hline Unhealthy & 96 & 28 & 1.00 & 1.00 & 1.00 \\
\hline Healthy & 8011 & 1598 & $0.68(0.45,1.06)$ & $0.61(0.40,0.96)$ & $0.45(0.29,0.73)$ \\
\hline
\end{tabular}

*N represents sample size for non-OSA group or for OSA group

${ }^{\dagger}$ Adjustment for age, sex, education, marital status, diabetes, dyslipidemia, retirement status, and all other healthy lifestyle factors

* Additional adjustment for body mass index

Table 3 Association between the healthy lifestyle score and OSA risk

\begin{tabular}{|c|c|c|c|c|c|}
\hline \multirow[t]{2}{*}{ Hlealthy lifestyle score } & \multicolumn{2}{|l|}{$\mathbf{N}^{*}$} & \multicolumn{3}{|l|}{ Effect } \\
\hline & Non-OSA group & OSA group & Unadjusted OR (95\% Cl) & Adjusted OR $(95 \% \mathrm{Cl})^{\dagger}$ & Adjusted OR $(95 \% \mathrm{Cl})^{\ddagger}$ \\
\hline $0-3$ & 684 & 272 & 1.00 & 1.00 & 1.00 \\
\hline 4 & 1166 & 303 & $0.65(0.54,0.79)$ & $0.71(0.59,0.87)$ & $0.68(0.56,0.84)$ \\
\hline 5 & 2310 & 514 & $0.56(0.47,0.66)$ & $0.68(0.56,0.82)$ & $0.71(0.59,0.86)$ \\
\hline 6 & 2772 & 438 & $0.40(0.33,0.47)$ & $0.51(0.42,0.62)$ & $0.62(0.51,0.76)$ \\
\hline 7 & 1175 & 99 & $0.21(0.16,0.27)$ & $0.29(0.22,0.37)$ & $0.49(0.37,0.65)$ \\
\hline$P$ for trend & & & $<0.001$ & $<0.001$ & $<0.001$ \\
\hline Every 1-point increment & & & $0.74(0.71,0.77)$ & $0.79(0.76,0.83)$ & $0.87(0.83,0.92)$ \\
\hline
\end{tabular}

*N represents sample size for non-OSA group or for OSA group

${ }^{\dagger}$ Adjustment for age, sex, education, marital status, retirement status, diabetes and dyslipidemia

${ }^{\ddagger}$ Additional adjustment for body mass index

mental status) were selected in our study to generate HLS, which can better reflect the overall lifestyle profile. In consistent with other studies on lifestyle integrating effect [16-18], four most common lifestyle components including active smoking, alcohol drinking, diet, and LTPA were also considered in our study. These four lifestyle factors were found to be highly correlated with the development of OSA $[4,13,20]$. Physical activity and diet, protected against OSA mainly by weight loss [13, 20, 37]. Overweight and obesity are widely recognized to be correlated with OSA and new prospective data showed that moderate weight gain in the general population might lead to an 
Table 4 Stratified analysis on the association between healthy lifestyle score and OSA risk by sex

\begin{tabular}{|c|c|c|c|c|c|c|c|c|}
\hline \multirow{2}{*}{$\begin{array}{l}\text { Healthy lifestyle } \\
\text { score }\end{array}$} & \multicolumn{4}{|l|}{ Male } & \multicolumn{4}{|l|}{ Female } \\
\hline & $\begin{array}{l}\text { Non- } \\
\text { OSA } \\
\text { group }\end{array}$ & OSA group & $\begin{array}{l}\text { Unadjusted OR } \\
(95 \% \mathrm{Cl})\end{array}$ & $\begin{array}{l}\text { Adjusted OR } \\
(95 \% \mathrm{Cl})^{*}\end{array}$ & Non-OSA group & OSA group & $\begin{array}{l}\text { Unadjusted OR } \\
(95 \% \mathrm{Cl})\end{array}$ & $\begin{array}{l}\text { Adjusted OR } \\
(95 \% \mathrm{CI})^{*}\end{array}$ \\
\hline $0-3$ & 558 & 234 & 1.00 & 1.00 & 126 & 38 & 1.00 & 1.00 \\
\hline 4 & 562 & 176 & $0.75(0.59,0.94)$ & $0.71(0.56,0.91)$ & 604 & 127 & $0.70(0.47,1.06)$ & $0.55(0.36,0.87)$ \\
\hline 5 & 627 & 213 & $0.81(0.65,1.01)$ & $0.78(0.61,0.99)$ & 1683 & 301 & $0.59(0.41,0.88)$ & $0.56(0.37,0.85)$ \\
\hline 6 & 500 & 144 & $0.69(0.54,0.87)$ & $0.71(0.55,0.93)$ & 2272 & 294 & $0.43(0.30,0.64)$ & $0.48(0.32,0.73)$ \\
\hline 7 & 222 & 37 & $0.40(0.27,0.57)$ & $0.55(0.37,0.82)$ & 953 & 62 & $0.22(0.14,0.34)$ & $0.38(0.24,0.62)$ \\
\hline$P$ for trend & & & $<0.001$ & 0.150 & & & $<0.001$ & 0.010 \\
\hline $\begin{array}{l}\text { Every 1-point incre- } \\
\text { ment }\end{array}$ & & & $0.87(0.82,0.92)$ & $0.89(0.84,0.95)$ & & & $0.72(0.67,0.77)$ & $0.86(0.79,0.93)$ \\
\hline
\end{tabular}

*Adjusted for age, education, marital status, diabetes, dyslipidemia, retirement status, and body mass index

Table 5 Stratified analysis on the association between healthy lifestyle score and OSA risk by retirement status

\begin{tabular}{|c|c|c|c|c|c|c|c|c|}
\hline \multirow{2}{*}{$\begin{array}{l}\text { Healthy } \\
\text { lifestyle score }\end{array}$} & \multicolumn{4}{|c|}{ Non-retirement } & \multicolumn{4}{|c|}{ Retirement } \\
\hline & $\begin{array}{l}\text { Non-OSA } \\
\text { group }\end{array}$ & OSA group & $\begin{array}{l}\text { Unadjusted OR } \\
(95 \% \mathrm{Cl})\end{array}$ & $\begin{array}{l}\text { Adjusted OR } \\
(95 \% \mathrm{Cl})^{*}\end{array}$ & $\begin{array}{l}\text { Non-OSA } \\
\text { group }\end{array}$ & OSA group & $\begin{array}{l}\text { Unadjusted OR } \\
(95 \% \mathrm{Cl})\end{array}$ & $\begin{array}{l}\text { Adjusted OR } \\
(95 \% \mathrm{Cl})^{*}\end{array}$ \\
\hline $0-3$ & 482 & 188 & 1.00 & 1.00 & 202 & 84 & 1.00 & 1.00 \\
\hline 4 & 638 & 149 & $0.60(0.47,0.76)$ & $0.65(0.50,0.86)$ & 528 & 154 & $0.70(0.51,0.96)$ & $0.82(0.59,1.15)$ \\
\hline 5 & 1122 & 190 & $0.43(0.35,0.55)$ & $0.64(0.49,0.83)$ & 1188 & 324 & $0.66(0.50,0.87)$ & $0.90(0.66,1.24)$ \\
\hline 6 & 1300 & 127 & $0.25(0.20,0.32)$ & $0.52(0.38,0.69)$ & 1472 & 311 & $0.51(0.38,0.68)$ & $0.82(0.60,1.13)$ \\
\hline 7 & 607 & 29 & $0.12(0.08,0.18)$ & $0.39(0.24,0.60)$ & 568 & 70 & $0.30(0.21,0.42)$ & $0.66(0.45,0.97)$ \\
\hline$P$ for trend & & & $<0.001$ & $<0.001$ & & & $<0.001$ & $<0.001$ \\
\hline $\begin{array}{l}\text { Every 1-point } \\
\text { increment }\end{array}$ & & & $0.66(0.62,0.70)$ & $0.83(0.77,0.89)$ & & & $0.79(0.74,0.84)$ & $0.93(0.87,1.01)$ \\
\hline
\end{tabular}

*Adjusted for age, sex, education, marital status, diabetes, dyslipidemia, and body mass index

Table 6 Stratified analysis on the association between healthy lifestyle score and OSA risk by history of dyslipidemia

\begin{tabular}{|c|c|c|c|c|c|c|c|c|}
\hline \multirow{2}{*}{$\begin{array}{l}\text { Healthy lifestyle } \\
\text { score }\end{array}$} & \multicolumn{4}{|c|}{ Non-dyslipidemia } & \multicolumn{4}{|l|}{ Dyslipidemia } \\
\hline & $\begin{array}{l}\text { Non- } \\
\text { OSA } \\
\text { group }\end{array}$ & OSA group & $\begin{array}{l}\text { Unadjusted OR } \\
(95 \% \mathrm{Cl})\end{array}$ & $\begin{array}{l}\text { Adjusted OR } \\
(95 \% \mathrm{Cl})^{*}\end{array}$ & Non-OSA group & OSA group & $\begin{array}{l}\text { Unadjusted OR } \\
(95 \% \mathrm{Cl})\end{array}$ & $\begin{array}{l}\text { Adjusted OR } \\
(95 \% \mathrm{CI})^{*}\end{array}$ \\
\hline $0-3$ & 192 & 58 & 1.00 & 1.00 & 492 & 214 & 1.00 & 1.00 \\
\hline 4 & 288 & 90 & $1.03(0.71,1.51)$ & $1.08(0.71,1.66)$ & 878 & 213 & $0.56(0.45,0.69)$ & $0.59(0.47,0.75)$ \\
\hline 5 & 680 & 133 & $0.65(0.46,0.92)$ & $0.74(0.50,1.11)$ & 1630 & 381 & $0.54(0.44,0.65)$ & $0.71(0.57,0.89)$ \\
\hline 6 & 917 & 109 & $0.39(0.28,0.56)$ & $0.55(0.37,0.84)$ & 1855 & 329 & $0.41(0.33,0.50)$ & $0.67(0.53,0.84)$ \\
\hline 7 & 420 & 24 & $0.19(0.11,0.31)$ & $0.40(0.23,0.69)$ & 755 & 75 & $0.23(0.17,0.30)$ & $0.55(0.40,0.75)$ \\
\hline$P$ for trend & & & $<0.001$ & $<0.001$ & & & $<0.001$ & $<0.001$ \\
\hline $\begin{array}{l}\text { Every 1-point incre- } \\
\text { ment }\end{array}$ & & & $0.69(0.64,0.75)$ & $0.79(0.71,0.87)$ & & & $0.76(0.73,0.80)$ & $0.91(0.86,0.97)$ \\
\hline
\end{tabular}

*Adjusted for age, sex, education, marital status, diabetes, retirement status, and body mass index

increase in the incidence and progression of OSA [43]. A meta-analysis showed that the single most effective way to reduce the incidence of OSA in a population is to prevent or reduce overweight and obesity [7]. Many studies have demonstrated physical activity- and diet-oriented lifestyle intervention plan played a leading role in weight loss [20, 44]. Reid's study found that moderate-to-severe OSA was associated with a less healthy dietary profile on account 
of reduced slow-wave sleep [13]. Diet and exercise were likely complementary, with the former inducing weight loss and improving OSA severity and the latter improving general well-being [20]. Effective diet and exercise modification programs could yield weight loss in the long-term, and weight control was potentially the best nonmedical means of treating or arresting the OSA progression in clinical settings, and reducing the prevalence of OSA and its associated sequelae in a public health context [4]. Smoking and alcohol drinking are often considered as risk factors for OSA with limited studies conducted to analyze this association. Smoking could increase sleep instability and airway inflammation, which is linked to OSA [4, 45]. In addition, smoking-related airway inflammation and disease may increase vulnerability to OSA [4]. Alcohol ingestion has been demonstrated to acutely increase nasal and pharyngeal resistance in awake subjects with increased number and duration of hypopnea and apnea events; administration of alcohol near bedtime could imply an adverse acute impact on breathing during sleep $[4,11]$. Hence, the control of smoking and alcohol drinking is of great significance for the prevention of OSA.

Among three new factors in generating HLS, a high household second-hand smoke exposure rate of $48.3 \%$ was found in China [25], and in our study exposure rate of passive smoking was $37.45 \%$ and $41.27 \%$ for the nonOSA group and the OSA group. Passive smokers might expose to hundreds of toxic and carcinogenic substances such as formaldehyde, benzene, and ammonia, which were related to the occurrence of serious respiratory diseases [25]. Therefore, passive smoking should be considered when assessing the smoking status of participants, apart from active smoking. The waist-hip ratio, an indicator of abdominal obesity, was even more strongly associated with obesity-related diseases. Increased abdominal fat appeared to be an independent predictor of risk in people who were not too high in BMI [28]. A review compared the predictive ability of BMI and waist-hip ratio for OSA and found that waist-hip ratio performed better than BMI because the accumulation of abdominal fat affected much more than peripheral fat as to the size and function of the upper airway [40]. Mental health is also an important component of lifestyle factors, and it is necessary to take the mental state into account when evaluating the overall effects of a healthy lifestyle. Current evidence suggested that depression can lead to difficulty falling asleep, frequent waking during the night and early morning, and a shortened rapid-eye-movement latency period [46]; persistent anxiety was independently associated with higher levels of sleep-disordered breathing [47]. In addition, depression and anxiety may bidirectionally be associated with OSA and they were often coexisted [14].
Among individual lifestyle factors, only passive smoking, waist-hip ratio, and mental status were associated with OSA risk, indicating the leading role of absence from second-hand smoke, weight loss, and healthy mental status in the protection of OSA as we have discussed above. Of note, the association between HLS and OSA risk was notably significant, even if not each lifestyle factor was associated with OSA risk. Stratified analysis by sex, retirement status, and history of dyslipidemia yielded consistent results with the main analysis that the risk of OSA de-escalated with the rise of HLS. Considering the higher prevalence of OSA in men, we conducted stratified analysis by sex and found that a healthy lifestyle played a protective effect against the occurrence of OSA among both males and females, especially for females. The reason for this disparity may be due to the hormonal influence on breathing control and upper airway muscle activation during sleep, resulting in 2 to 3 times more men are affected by OSA than premenopausal age-matched women [7]. The stratified analysis by retirement status identified that OSA risk decreased with increasing HLS among nonretired participants and HLS of more than 6 points was found to have a protective effect on OSA in the retired participants. This result was reasonable since the retirees tended to be older, and the physical damage from years of work negatively affected both women's and men's physical functioning in old age [48]. Retirement may indeed be associated with changes in lifestyle, but the impact may be heterogeneous depending on the type of lifestyle, lifestyle indicators, and the personal situation of the retiree [49]. LTPA seems to increase slightly after retirement in most studies, especially moderate-intensive physical activity, while for dietary habits, smoking, and alcohol drinking, there is not enough evidence to draw any conclusion [49]. Due to the consideration that dyslipidemia may lead to increased sympathetic activity, oxidative stress, insulin resistance, and endothelial dysfunction, thereby affecting the occurrence and development of OSA [50], the stratified analysis by the history of dyslipidemia was conducted and a similar protective effect was observed in both nondyslipidemia and dyslipidemia groups.

There are several strengths. First, this is the first largescale study among Chinese adults to investigate the association of combined effects of lifestyle factors with OSA risk and develop an indicator of HLS comprehensively considering physical and mental status. Our results provided useful clues for further longitudinal studies. Second, the multi-stage sampling method potentiated the representativeness of participants and the large sample size increased the statistic power. Third, the fact that multiple stratified analyses and sensitivity analyses displayed accordant results, indicating good internal consistency for the HLS evaluated. 
Some limitations exist in this study as well. First, the crosssectional design limited the ability of causal inference and was susceptible to bias. Second, the OSA assessment was based on the Berlin Questionnaire but not polysomnography, so we could not determine the severity of OSA. However, Berlin Questionnaire has been validated and specially developed for the primary care setting [21], which was suitable for this population-based study. We also used STOPBang Questionnaire to determine OSA in sensitivity analysis and then got consistent results, reflecting that our results are credible to a large degree. Third, the components of HLS and the cut-offs for each lifestyle factor were selected based on OSA-related clinical guidelines and without uniform criteria. Nevertheless, seven components were significantly correlated with HLS and no collinearity was found among these lifestyle factors. Moreover, we did seven repeated analyses by excluding each of the seven components of HLS each time and got similar results with the main analysis, demonstrating the stability of HLS. Fourth, a simplified diet quality score was used due to the lack of standard or recognized dietary scoring systems for OSA, which might not adequately clarify the complexity and reliability of diet. There is an urgent need to develop a dietary guideline specifically for OSA.

\section{Conclusions}

The results suggest that HLS reflecting the combined effect of multiple-dimensional lifestyle factors was inversely associated with OSA risk. Preventive strategies integrating multiple lifestyle factors may provide a more feasible approach for OSA prevention.

\section{Abbreviations \\ BMI: Body mass index; BQ: Berlin questionnaire; CES-D: The Center for Epidemiologic Studies Depression Scale; Cls: Confidence intervals; FFQ: Food frequency questionnaire; GZHS: Guangzhou Heart Study; HLS: Healthy lifestyle score; LTPA: Leisure-time physical activity; MET: Metabolic equivalent; ORs: Odds ratios; OSA: Obstructive sleep apnea; SAS: Self-rating Anxiety Scale; WHO: World health organization; WHR: Waist-hip ratio.}

\section{Supplementary Information}

The online version contains supplementary material available at https://doi. org/10.1186/s12890-021-01818-7.

Additional file 1: Table S1. Description and scoring criteria of lifestyle fac tors. Table S2. The correlation between each lifestyle factor and healthy lifestyle score. Table S3. Association of every 1-unit increment of healthy lifestyle score with OSA risk after excluding each factor in turn. Table S4 Sensitivity analysis on the association between healthy lifestyle score and OSA risk after further adjusting for neck circumference. Table S5. Association between the healthy lifestyle score and OSA risk based on STOP-Bang Questionnaire. Table S6. Association between healthy lifestyle score and OSA risk by using median in place of WHO recommended cut-off value of LTPA in generating HLS. Table S7. Sensitivity analysis on the association between healthy lifestyle score and OSA risk after excluding participants aged 65 years and above. Table S8. Sensitivity analysis on the association between healthy lifestyle score and OSA risk after excluding participants with BMI less than $18.5 \mathrm{~kg} / \mathrm{m}^{2}$

\section{Acknowledgements}

The authors would like to thank epidemiologists, nurses, and doctors in Guangdong Provincial People's Hospital, in Guangzhou Center for Disease Control and Prevention, and in community healthcare centers in data collection, and thank all study subjects for their participation.

\section{Authors' contributions}

XDL and HD conceived and designed the study; XRD, MRZ, JH, HD, HYL and $\mathrm{LXL}$ collected the data, XRD analyzed the data, XRD, JH and MRZ drafted the manuscript, WJZ, ZWW, JHL, WQC, HD and XDL reviewed and edited the manuscript. All authors read and approved the final manuscript.

\section{Funding}

This work was supported by the Science and Technology Program of Guangzhou City (No.202102080404), the Guangdong Basic and Applied Basic Research Foundation (No. 2019A1515011599), the National Key R\&D Program of China (No.2018YFC1312502), and the Guangdong Provincial Key R\&D Program (No.2019B020230004).

\section{Availability of data and materials}

The data used to support the findings of this study are available from the corresponding author upon request. A proposal with detailed description of study objectives and statistical analysis plan will be needed for evaluation of the reasonability of requests if someone requests data sharing.

\section{Declarations}

\section{Ethics approval and consent to participate}

This study was approved by the Ethical Committee of Guangdong Provincial People's Hospital and Ethical Review Committee for Biomedical Research, School of Public Health, Sun Yat-sen University. The study was performed in accordance with the Declaration of Helsinki and written informed consent was obtained from each participant before they joined in the study.

\section{Consent for publication}

All co-authors provided comments and approved the final version.

\section{Competing interests}

The authors state that they have no conflicts of interest.

\section{Author details}

${ }^{1}$ Department of Epidemiology, School of Public Health, Sun Yat-Sen University, 7/F, Public Health Building, No.74, Zhongshan Second Road, Guangzhou 510080, China. ${ }^{2}$ School of Public Health, Guangdong Pharmaceutical University, No. 283 Jianghai Avenue, Haizhu District, Guangzhou 510310, China. ${ }^{3}$ Department of Geriatrics, Institute of Geriatrics, Guangdong Provincial People's Hospital, Guangzhou, China. ${ }^{4}$ Guangzhou Center for Disease Control and Prevention, Guangzhou, China. ${ }^{5}$ School of Public Health and Emergency Management, Southern University of Science and Technology, Shenzhen, China. ${ }^{6}$ Department of Cardiology, Guangdong Cardiovascular Institute, Guangdong Provincial People's Hospital/Guangdong Academy of Medical Science, 5/F, Ying Tung Building, No.106, Zhongshan Second Road, Guangzhou 510080, China. ${ }^{7}$ Shantou University Medical College, Shantou, China.

Received: 28 July 2021 Accepted: 31 December 2021

Published online: 11 January 2022

\section{References}

1. Veasey SC, Rosen IM. Obstructive sleep apnea in adults. N Engl J Med. 2019;380(15):1442-9. https://doi.org/10.1056/NEJMcp1816152.

2. Patel SR. Obstructive sleep apnea. Ann Intern Med. 2019;171(11):ITC8196. https://doi.org/10.7326/AITC201912030.

3. Senaratna CV, Perret JL, Lodge CJ, Lowe AJ, Campbell BE, Matheson MC, Hamilton GS, Dharmage SC. Prevalence of obstructive sleep apnea in the general population: a systematic review. Sleep Med Rev. 2017;34:70-81. https://doi.org/10.1016/j.smrv.2016.07.002. 
4. Young T, Peppard PE, Gottlieb DJ. Epidemiology of obstructive sleep apnea: a population health perspective. Am J Respir Crit Care Med. 2002;165(9):1217-39. https://doi.org/10.1164/rccm.2109080.

5. Benjafield AV, Ayas NT, Eastwood PR, Heinzer R, I P MSM, Morrell MJ, Nunez CM, Patel SR, Penzel T, Pépin J-L, et al. Estimation of the global prevalence and burden of obstructive sleep apnoea: a literature-based analysis. Lancet Respir Med. 2019;7(8):687-98. https://doi.org/10.1016/ S2213-2600(19)30198-5.

6. Bradley TD, Floras JS. Obstructive sleep apnoea and its cardiovascular consequences. The Lancet. 2009;373(9657):82-93. https://doi.org/10. 1016/S0140-6736(08)61622-0.

7. Lévy P, Kohler M, McNicholas WT, Barbé F, McEvoy RD, Somers VK, Lavie L, Pépin J-L. Obstructive sleep apnoea syndrome. Nat Rev Dis Primers. 2015;1 (1):15015. https://doi.org/10.1038/nrdp.2015.15.

8. Hall KA, Singh M, Mukherjee S, Palmer L. Physical activity is associated with reduced prevalence of self-reported obstructive sleep apnea in a large, general population cohort study. J Clin Sleep Med. 2020;16(7):1179-87. https://doi.org/10.5664/jcsm.8456.

9. Simpson L, McArdle N, Eastwood PR, Ward KL, Cooper MN, Wilson AC, Hillman DR, Palmer $\amalg$, Mukherjee S. Physical inactivity is associated with moderate-severe obstructive sleep apnea. J Clin Sleep Med. 2015;11(10):1091-9. https://doi.org/10.5664/jcsm.5078.

10. Noal RB, Menezes AM, Canani SF, Siqueira FV. Habitual snoring and obstructive sleep apnea in adults: population-based study in Southern Brazil. Rev Saude Publica. 2008:42(2):224-33. https://doi.org/10.1590/ s0034-89102008000200006.

11. Choudhury A, Routray D, Swain S, Das AK. Prevalence and risk factors of people at-risk of obstructive sleep apnea in a rural community of Odisha, India: a community based cross-sectional study. Sleep Med. 2019;58:42-7. https://doi.org/10.1016/j.sleep.2019.03.014.

12. Al-Qattan $\mathrm{H}$, Al-Omairah $\mathrm{H}$, Al-Hashash $\mathrm{K}$, Al-Mutairi F, Al-Mutairat $\mathrm{M}$, Al-Ajmi M, Mohammad A, Alterki A, Ziyab AH. Prevalence, risk factors, and comorbidities of obstructive sleep apnea risk among a working population in Kuwait: a cross-sectional study. Front Neurol. 2021;12:620799620799. https://doi.org/10.3389/fneur.2021.620799.

13. Reid M, Maras JE, Shea S, Wood AC, Castro-Diehl C, Johnson DA, Huang T, Jacobs DR Jr, Crawford A, St-Onge MP, et al. Association between diet quality and sleep apnea in the multi-ethnic study of atherosclerosis. Sleep. 2019;42(1):zsy194. https://doi.org/10.1093/sleep/zsy194.

14. Andrews JG, Oei TP. The roles of depression and anxiety in the understanding and treatment of Obstructive Sleep Apnea Syndrome. Clin Psychol Rev. 2004;24(8):1031-49. https://doi.org/10.1016/j.cpr.2004.08. 002.

15. Gupta MA, Simpson FC. Obstructive sleep apnea and psychiatric disorders: a systematic review. J Clin Sleep Med. 2015;11 (2):165-75. https://doi. org/10.5664/jcsm.4466.

16. Carr PR, Weigl K, Jansen L, Walter V, Erben V, Chang-Claude J, Brenner $\mathrm{H}$, Hoffmeister $\mathrm{M}$. Healthy lifestyle factors associated with lower risk of colorectal cancer irrespective of genetic risk. Gastroenterology. 2018;155(6):1805-1815.e1805. https://doi.org/10.1053/j.gastro.2018.08. 044

17. Zhu N, Yu C, Guo Y, Bian Z, Han Y, Yang L, Chen Y, Du H, Li H, Liu F, et al. Adherence to a healthy lifestyle and all-cause and cause-specific mortality in Chinese adults: a 10-year prospective study of 0.5 million people. Int J Behav Nutr Phys Act. 2019;16(1):98-98. https://doi.org/10.1186/ s12966-019-0860-Z.

18. Li Y, Schoufour J, Wang DD, Dhana K, Pan A, Liu X, Song M, Liu G, Shin $\mathrm{HJ}$, Sun Q, et al. Healthy lifestyle and life expectancy free of cancer, cardiovascular disease, and type 2 diabetes: prospective cohort study. BMJ. 2020;368:16669-16669. https://doi.org/10.1136/bmj.l6669.

19. Chinese Medical Association CMJPH, Chinese Society of General Practice, Sleep Related Breathing Disorders Group of Chinese Thoracic Society, Editorial Board of Chinese Journal of General Practitioners of Chinese Medical Association, Expert Group of Primary Guidelines for Primary Care of Respiratory System Disease: Guideline for primary care of adult obstructive sleep apnea (2018). Chin J Gen Pract 2019; 18(1):21-29. https://doi.org/10.3760/cma.j.jissn.1671-7368.2019.01.007

20. Hudgel DW, Patel SR, Ahasic AM, Bartlett SJ, Bessesen DH, Coaker MA, Fiander PM, Grunstein RR, Gurubhagavatula I, Kapur VK, et al. The role of weight management in the treatment of adult obstructive sleep apnea. An Official American Thoracic Society Clinical Practice Guideline. Am 」
Respir Crit Care Med. 2018;198(6):70-87. https://doi.org/10.1164/rccm. 201807-1326ST.

21. Gottlieb DJ, Punjabi NM. Diagnosis and management of obstructive sleep apnea: a review. JAMA. 2020;323(14):1389-400. https://doi.org/10.1001/ jama.2020.3514.

22. Duan X, Zheng M, He S, Lao L, Huang J, Zhao W, Lao XQ, Deng H, Liu X. Association between physical activity and risk of obstructive sleep apnea. Sleep Breath. 2021. https://doi.org/10.1007/s11325-021-02318-y.

23. Deng $H$, Guo $P$, Zheng M, Huang J, Xue Y, Zhan X, Wang F, Liu Y, Fang $X$, Liao $H$, et al. Epidemiological characteristics of atrial fibrillation in southern china: results from the Guangzhou Heart Study. Sci Rep. 2018;8(1):17829. https://doi.org/10.1038/s41598-018-35928-w.

24. Tan A, Yin JDC, Tan LWL, van Dam RM, Cheung YY, Lee C-H. Using the Berlin Questionnaire to predict obstructive sleep apnea in the general population. J Clin Sleep Med. 2017;13(3):427-32. https://doi.org/10.5664/ jcsm.6496.

25. Wang CP, Ma SJ, Xu XF, Wang JF, Mei CZ, Yang GH. The prevalence of household second-hand smoke exposure and its correlated factors in six counties of China. Tob Control. 2009;18(2):121-6. https://doi.org/10.1136/ tc.2008.024836.

26. Society CN. The Chinese dietary guidelines. Beijing: People's Medical Publishing House; 2016

27. Després J-P, Lemieux I. Abdominal obesity and metabolic syndrome. Nature. 2006;444(7121):881-7. https://doi.org/10.1038/nature05488.

28. World Health Organization. Waist Circumference and Waist-Hip Ratio Report of a WHO Expert Consultation. 2008, https://apps.who.int/iris/bitst ream/handle/10665/44583/9789241501491_eng.pdf;jsessionid=CA4D2 2D1CA09435COC678588386EEB2F? sequence $=1$.

29. World Health Organization. Global Physical Activity Questionnaire (GPAQ). 2018, https://www.who.int/ncds/surveillance/steps/GPAQ_EN.pdf.

30. World Health Organization. WHO guidelines on physical activity and sedentary behaviour. 2020, https://apps.who.int/iris/bitstream/handle/ 10665/336656/9789240015128-eng.pdf? sequence $=1$ \&isAllowed $=y$.

31. Radloff LS. The CES-D Scale: A self-report depression scale for research in the general population. Appl Psychol Meas. 1977;1:385-401. https://doi. org/10.1177/014662167700100306.

32. Zung WW. A rating instrument for anxiety disorders. Psychosomatics. 1971;12(6):371-9. https://doi.org/10.1016/s0033-3182(71)71479-0.

33. World Health Organization. Classification of diabetes mellituS 2019. 2019, https://www.who.int/publications-detail/classification-of-diabetes-melli tus.

34. China adult dyslipidemia control guidelines revision joint committee: Guidelines for the prevention and treatment of dyslipidemia in Chinese adults (revised edition, 2016). Chin Circul J. 2016; 31 (10). https://doi.org/ 10.3969/j.issn.1000-3614.2016.10.001.

35. Chiu HY, Chen PY, Chuang LP, Chen NH, Tu YK, Hsieh YJ, Wang YC, Guilleminault C. Diagnostic accuracy of the Berlin questionnaire, STOP-BANG, STOP, and Epworth sleepiness scale in detecting obstructive sleep apnea: A bivariate meta-analysis. Sleep Med Rev. 2017;36:57-70. https://doi.org/ 10.1016/j.smrv.2016.10.004.

36. Issa FG, Sullivan CE. Alcohol, snoring and sleep apnea. J Neurol Neurosurg Psychiatry. 1982;45(4):353-9. https://doi.org/10.1136/jnnp.45.4.353.

37. Murillo R, Reid KJ, Arredondo EM, Cai J, Gellman MD, Gotman NM, Marquez DX, Penedo FJ, Ramos AR, Zee PC, et al. Association of self-reported physical activity with obstructive sleep apnea: results from the Hispanic Community Health Study/Study of Latinos (HCHS/SOL). Prev Med. 2016;93:183-8. https://doi.org/10.1016/j.ypmed.2016.10.009.

38. Georgoulis M, Yiannakouris N, Kechribari I, Lamprou K, Perraki E, Vagiakis E, Kontogianni MD. The effectiveness of a weight-loss Mediterranean diet/lifestyle intervention in the management of obstructive sleep apnea: results of the "MIMOSA" randomized clinical trial. Clin Nutr. 2021;40(3):850-9. https://doi.org/10.1016/j.clnu.2020.08.037.

39. Lin YN, Li QY, Zhang XJ. Interaction between smoking and obstructive sleep apnea: not just participants. Chin Med J. 2012;125(17):3150-6. https://doi.org/10.3760/cma.j.issn.0366-6999.2012.17.033.

40. Seidell JC. Waist circumference and waist/hip ratio in relation to all-cause mortality, cancer and sleep apnea. Eur J Clin Nutr. 2010;64(1):35-41. https://doi.org/10.1038/ejcn.2009.71.

41. Liu X, Chen J, Zhou J, Liu J, Lertpitakpong C, Tan A, Wu S, Mao Z. The Relationship between the number of daily health-related behavioral risk 
factors and sleep health of the elderly in China. Int J Environ Res Public Health. 2019;16(24):4905. https://doi.org/10.3390/ijerph16244905.

42. Tadayon M, Illkhani M, Abedi P, Haghighi Zadeh M. The relationship between sleep quality and lifestyle in postmenopausal Iranian women: a cross-sectional study. Women Health. 2019;59(8):883-91. https://doi.org/ 10.1080/03630242.2019.1607802.

43. Young T, Peppard PE, Gottlieb DJ. Epidemiology of obstructive sleep apnea. Am J Respir Crit Care Med. 2002;165(9):1217-39. https://doi.org/ $10.1164 / \mathrm{rccm} .2109080$.

44. Tuomilehto HPI, Seppä JM, Partinen MM, Peltonen M, Gylling H, Tuomilehto JOI, Vanninen EJ, Kokkarinen J, Sahlman JK, Martikainen T, et al. Lifestyle intervention with weight reduction. Am J Respir Crit Care Med. 2009;179(4):320-7. https://doi.org/10.1164/rccm.200805-6690C.

45. Hsu W-Y, Chiu N-Y, Chang C-C, Chang T-G, Lane H-Y. The association between cigarette smoking and obstructive sleep apnea. Tob Induc Dis. 2019;17:27-27. https://doi.org/10.18332/tid/105893.

46. Schröder CM, O'Hara R. Depression and obstructive sleep apnea (OSA). Ann Gen Psychiatry. 2005;4:13-13. https://doi.org/10.1186/ 1744-859X-4-13.

47. Lehto SM, Sahlman J, Soini EJ, Gylling H, Vanninen E, Seppä J, Viinamäki H, Tuomilehto $\mathrm{H}$. The association between anxiety and the degree of illness in mild obstructive sleep apnoea. Clin Respir J. 2013;7(2):197-203. https:// doi.org/10.1111/j.1752-699X.2012.00304.X.

48. Nilsen C, Agahi N, Kåreholt I. Work stressors in late midlife and physical functioning in old age. J Aging Health. 2016;29(5):893-911. https://doi. org/10.1177/0898264316654673.

49. Zantinge EM, van den Berg M, Smit HA, Picavet HSJ. Retirement and a healthy lifestyle: opportunity or pitfall? A narrative review of the literature. Eur J Pub Health. 2014;24(3):433-9. https://doi.org/10.1093/eurpub/ ckt157.

50. Barros D, García-Río F. Obstructive sleep apnea and dyslipidemia: from animal models to clinical evidence. Sleep. 2019;42(3):zsy236. https://doi. org/10.1093/sleep/zsy236.

\section{Publisher's Note}

Springer Nature remains neutral with regard to jurisdictional claims in published maps and institutional affiliations.

Ready to submit your research? Choose BMC and benefit from:

- fast, convenient online submission

- thorough peer review by experienced researchers in your field

- rapid publication on acceptance

- support for research data, including large and complex data types

- gold Open Access which fosters wider collaboration and increased citations

- maximum visibility for your research: over $100 \mathrm{M}$ website views per year

At BMC, research is always in progress.

Learn more biomedcentral.com/submissions 